\title{
Nasarre Aznar, Sergio. La gran apuesta. Avaricia. El beneficio sin responsabilidad. Tirant lo Blanch [Colección Cine y Derecho]: Valencia, 2021.
}

\author{
Ángeles Galiana Saura \\ Área de Filosofía del Derecho \\ Universitat Rovira i Virgili
}

Fecha de recepción 30/04/2021 I De publicación: 24/06/2021

El libro La gran apuesta. Avaricia. El beneficio sin responsabilidad de Sergio Nasarre Aznar forma parte de la excelente colección sobre Cine y Derecho de la editorial Tirant lo Blanch, que nació en su primera etapa hace más de dieciocho años, en el 2002 y que, en esta segunda etapa iniciada a finales de 2020 y dirigida por Javier de Lucas y Fernando Flores, ya cuenta con seis nuevos volúmenes, de los cuales el número 3 es el que se reseña a continuación. La colección fue un reto arriesgado y complicado en su día, fruto del empeño y tesón de los profesores Javier de Lucas y Mario Ruiz (este último añorado profesor y compañero, tanto de la que suscribe, como del autor Sergio Nasarre), con la pretensión de atraer hacia el derecho a un público interesado -más allá del estrictamente jurista- que quisiera acceder a él desde el cine. Dicha colección, además, cabe destacar que ha sido distinguida con la Medalla de Oro al Mérito en las Bellas Artes en diciembre de 2020.

Este volumen se basa en la película The big short (2015), que parte de la crisis financiera mundial del año 2007 y que analiza un experto en la materia, el profesor Nasarre, quien ha dedicado los últimos años a una extensa y minuciosa investigación sobre la crisis de la vivienda (véase su reciente obra Los años de la crisis de la vivienda, Tirant lo Blanch, 2020). Especialmente incide el autor sobre los condicionantes jurídicos que provocaron dicha crisis en Estados Unidos y las consecuencias en nuestro país, partiendo de la afirmación de que la crisis de la vivienda, financiera y económica de 2007 está en la distorsión de los principios civiles del derecho con el fin de maximizar los beneficios económicos.

El libro se divide en cuatro grandes partes: la primera, sobre la contextualización de la problemática entorno a la crisis financiera y económica que se desencadenó en el 2007 y que se centra en la avaricia, elección del autor para el subtítulo de este libro, pues considera su autor que fue el pecado capital que detonó que conllevó a la posterior crisis; las dos siguientes tratan, respectivamente, sobre los grupos de protagonistas (quiénes son, qué hacen, que les mueve a ello, etc.), y la trama de la película 
(que se subdivide, a su vez, en tres partes: la primera, en qué consistía el negocio de la industria de la titulización hipotecaria y cuál era el marco regulatorio que la regía, el cual favoreció el abuso y la posterior crisis; la segunda, que se centra en la actuación de los protagonistas de apostar contra el sistema; y, la tercera, que aborda cómo se aceleró todo el año 2007); y, finamente, una cuarta parte donde el profesor Nasarre recopila sus principales observaciones entorno a la crisis de la vivienda desde 2007 hasta 2020 fruto de su labor investigadora durante esos años y que consolidó con la promoción de la creación y dirección de la Cátedra UNESCO de Vivienda de la Universitat Rovira i Virgili el año 2013. En esta cuarta parte, arrancando de los últimos minutos de la película, el autor sintetiza algunas de las consecuencias de la crisis hasta nuestros días que ha coincidido con una nueva crisis, la del COVID-19. Finalmente, como anexo, el autor incluye los 65 twits diarios que publicó en su cuenta durante el confinamiento sobre las causas y las consecuencias de la crisis de 2007, con la finalidad de poder ayudar a evitar una nueva.

La avaricia, tal y como indica el profesor Nasarre, se puede considerar como un tipo de codicia, que es a su vez un término más genérico, porque si bien en los dos hay un afán "desmedido" o "excesivo", en la avaricia se exige que sea para poseerlas y atesorarlas, mientras que, en la codicia no necesariamente. La avaricia, como señala el autor, se encuentra en el origen de la crisis de 2007 y es el eje sobre el que gira la película. En él todo el mundo es avaricioso, tanto los que desarrollan el mainstream financiero de la titulización hipotecaria, como los protagonistas, que apuestan contra ese sistema. La película, en este sentido, señala el profesor Nasarre que refleja adecuadamente los engranajes que, a grandes rasgos, produjeron la crisis de 2007: la avaricia de la sociedad de consumo, también proyectada en el acceso a la vivienda; la de los que aspiraban a comprarse una segunda residencia en Aspen; la de los advenedizos de las finanzas en busca de dinero fácil y rápido; etc.

Señala el profesor Nasarre que sorprende que el director, Adam McKay, que había sido comediante, tratase un tema tan complejo, y que quizás lo hiciera con la finalidad de provocar, causar indignación al espectador. En este sentido, la película resulta compleja para comprender realmente la generación de la crisis financiera de 2007, pero quizás eso es lo que precisamente su director pretendía: no mostrar realmente a todos los responsables y a todos los que se beneficiaron de alguna manera. Su finalidad parece ser la que pretende indicar al inicio de la película con la frase de Mark Twain "It ain't what yo don't know that gets you into trouble. It's what you know for sure that just ain't so", que según Nasarre parece que quiere señalar que es peligroso actuar creyéndote que lo que tú opinas sea una certeza 
cuando realmente es solamente una opinión y no un hecho refutable. No obstante, y tal y como bien indica el autor, las opiniones no fundamentadas no deberían tener el mismo valor que las que lo están. En este sentido, la película se centra en aquellos pocos que previeron el posible colapso de las finanzas, de la economía y de la vivienda, pero que no pusieron ese conocimiento a disposición de todos para advertir de que, si todo seguía así acabaría mal para mucha gente, especialmente para los más humildes. El profesor Nasarre publicó, ya en el año 2004, un libro (Securitization and mortgage bonds: legal aspects and harmonization in Europe) donde advertía de que la titulización era insostenible, con lo cual era algo conocido -al menos, por quienes estudiaron el tema-.

La película The big short resulta original no por ser la primera sobre la temática, ni mucho menos, pues incluso puede resultar más interesante el documental Inside Job (2011), sino por la perspectiva desde la que se describe: tres grupos de especuladores que apuestan contra la tendencia del mercado por diversos motivos, pero con la misma finalidad de acumular dinero. De ahí que el profesor Nasarre considere necesario dedicar un capítulo de este libro a analizar la actitud de los personajes de la trama.

En el capítulo tercero, se explica la titulización o conversión de hipotecas sobre inmuebles en valores negociables. Los valores hipotecarios dan cierta estabilidad a la financiación y, en ocasiones, liberan de riesgo a quien concede los préstamos hipotecarios. El autor analiza y explica claramente las diferencias entre las diversas tipologías de conversiones, su origen, especialmente en la cesión de créditos hipotecarios, y que lo que sucedió con los re-empaquetamientos de títulos hipotecarios que, como señala Nasarre "era un tema de cómo contorsionar el Derecho, cómo desnaturalizarlo con un único fin: hacer más dinero utilizando como excusa el incentivado interés de todo americano o recién llegado de ser propietario de una o más viviendas". En este sentido, indica que existían una serie de condicionantes legales en el sistema norteamericano de creación, gestión, cesión y ejecución de créditos hipotecarios, que inevitablemente dieron lugar a la crisis de 2007, además de la ausencia de una autoridad financiera de control fuerte y de la ausencia de alguna normativa sobre titulización hipotecaria, cuestión ésta que desarrolla con mayor detenimiento advirtiendo de hasta diez causas o ingredientes (según la terminología del autor), que dieron lugar a la gran crisis del 2007 y que no todos aparecen en el film. De todas ellos, creo interesante destacar el relacionado con la existencia de un sistema de refinanciación hipotecaria (titulización) fundamentado en el riesgo moral, debido a cuatro elementos: 1) la falta de ética en la profesión bancaria y de las finanzas (que aparece en diversas escenas del film); 2) el riesgo moral en la intermediación inmobiliaria y de préstamos hipotecarios; 3) el riesgo moral estructural del sistema 
angloamericano de titulización hipotecaria y de demás activos, pues quien concede los préstamos no sufre la consecuencia de sus posibles impagos, sino que lo hace el adquirente de esos valores o sus sucedáneos y; 4) el riesgo moral de los directivos y cargos intermedios de bancos y financieras.

De ahí, precisamente el otro subtítulo de este libro "El beneficio sin responsabilidad". Como señala su autor, resulta esencial la distorsión legal que supone la disociación entre beneficio y responsabilidad, pues en el momento en que se legitima masivamente un mecanismo por el cual todos los riesgos (incluido el impago) de los préstamos hipotecarios que se conceden los asumirá otro cada vez se concederán préstamos más arriesgados. Esto es lo que dio lugar al aumento de la morosidad y los impagos hipotecarios en Estados Unidos. Todo en ello en ausencia de un marco regulatorio, una zona de alegalidad.

La compra en "corto" o apuesta en corto es el es el eje principal de la película, pues hacen una apuesta contra el buen funcionamiento del mercado hipotecario; es decir, ellos ganan dinero si los prestatarios impagan masivamente, y dado que las posibilidades de ganarla eran muy bajas, los costes de contratarlos eran bajos y las expectativas de ganancias eran enormes. Esa seguridad en el sistema, como se menciona en varias veces en la película, parte de las asunciones de que no solo el precio de las viviendas es muy estable y que no baja, sino que los préstamos hipotecarios son lo último que dejan de pagar los hogares. Una peculiaridad de la industria financiera norteamericana fue que los cargos intermedios son quienes se llevan los bonus si una operación va bien pero el riesgo, si algo va mal, se lo lleva la empresa. En este sentido, estamos ante otro nuevo riesgo moral de disociación entre beneficio y responsabilidad y las perniciosas consecuencias que conlleva: a arriesgarse cada vez más en operaciones, sin asumir una responsabilidad personal. A nivel de discusión moral, y bajo la excusa de que "hacían lo que mandaban" para exculparse moral y jurídicamente, en el caso de la crisis financiera, el problema fue realmente que el sistema legal norteamericano permitía "riesgos morales" a lo largo de todo el proceso titulizador, no haciendo a nadie realmente responsable por sus propios actos y permitiendo escurrir la responsabilidad al siguiente apostante en el sistema.

Remarca el profesor Nasarre que estamos desde 2007 en un laberinto en el cual los que tienen ingresos más modestos no pueden acceder ni a través de la propiedad ni a través del alquiler a una vivienda en las ciudades donde deben residir, normalmente por motivos laborales. La falta de reformas estructurales en las formas de tenencias de la vivienda tradicionales y la pasividad a nivel estatal de establecer un marco legal adecuado para el nacimiento de nuevas, desoyendo incluso los consejos a este 
respecto de la Nueva Agenda Urbana (2016), está perjudicando el cumplimiento efectivo del derecho a una vivienda digna y dejando como única alternativa posible el alquilar precariamente para muchas personas.

A modo de conclusión, el autor señala que la película consigue algo que a priori era muy difícil: hacer comprender grosso modo al espectador lego qué hicieron una serie de financieros para enriquecerse mientras el resto se empobrecieron. No obstante, él mismo afirma que no está seguro de que la película haya alcanzado lo que pretendía su director en cuanto a ser pedagógico y moralizante: que todo el mundo comprendiese las causas de la generación de la crisis, pues no las menciona todas, y lo perverso del mundo de las finanzas que la facilitaron. A pesar de que la película caracteriza muy bien cual fue el rol de cada uno de los intervinientes en el proceso de titulización y qué hicieron mal cada uno, falla a la hora de evidenciar al espectador cuál es realmente el quid de la cuestión y que en este trabajo su autor ha querido resaltar: que todo fue provocado por una cadena de riesgos morales debido a cómo estaba estructurado el sistema de titulalización hipotecaria norteamericano que permitía que aquél que concedía el préstamo pudiese deshacerse de su riesgo de impago rápidamente y pasarlo al mercado financiero. Pero creo especialmente interesante destacar, sobre todo, que se permitió disociar beneficio y responsabilidad, lo cual conllevó el no ser prudente ni poner límites a la codicia. Por todo ello recomiendo encarecidamente el brillante análisis que realiza el profesor Nasarre en este libro. 